\title{
Reassessing Revascularization
} Strategies in Coronary Artery Disease and Type 2 Diabetes Mellitus

\author{
Bo Liang ${ }^{1 \dagger}$, Xin $\mathrm{He}^{1 \dagger}$ and Ning $\mathrm{Gu}^{2 *}$ \\ ${ }^{1}$ Nanjing University of Chinese Medicine, Nanjing, China, ${ }^{2}$ Nanjing Hospital of Chinese Medicine Affiliated to Nanjing \\ University of Chinese Medicine, Nanjing, China
}

OPEN ACCESS

Edited by:

Liang Rui,

Kunming Medical University, China

Reviewed by:

Xing Chang,

China Academy of Chinese Medical

Sciences, China

Jen-Tsung Chen,

National University of

Kaohsiung, Taiwan

Wawaimuli Arozal,

University of Indonesia, Indonesia

${ }^{*}$ Correspondence:

Ning Gu

guning@njucm.edu.cn

tThese authors have contributed equally to this work

Specialty section:

This article was submitted to Coronary Artery Disease,

a section of the journal

Frontiers in Cardiovascular Medicine

Received: 09 July 2021

Accepted: 16 September 2021

Published: 21 October 2021

Citation:

Liang B, He X and Gu N (2021)

Reassessing Revascularization

Strategies in Coronary Artery Disease

and Type 2 Diabetes Mellitus.

Front. Cardiovasc. Med. 8:738620.

doi: 10.3389/fcrm.2021.738620
Percutaneous coronary intervention (PCI) or coronary artery bypass grafting (CABG) is still controversial in patients with coronary artery disease (CAD) and type 2 diabetes mellitus (T2DM). Here, we aimed to evaluate the long-term follow-up events of PCl and CABG in these populations. Relevant randomized controlled trials were retrieved from PubMed, Embase, and the Cochrane databases. The pooled results were represented as risk ratios (RRs) with 95\% confidence intervals (Cls) with STATA software. A total of six trials with 1,766 patients who received $C A B G$ and 2,262 patients who received $\mathrm{PCl}$ were included in our study. Patients in the CABG group were significantly associated with a lower all-cause mortality compared with those in the $\mathrm{PCl}$ group ( $R R=0.74$, $95 \% \mathrm{Cl}=0.56-0.98, P=0.037)$. Cardiac mortality, recurrent myocardial infarction, and repeat revascularization were also significantly lower in the CABG group $(R R=0.79$, 95\% $\mathrm{Cl}=0.40-1.53, P=0.479 ; \mathrm{RR}=0.70,95 \% \mathrm{Cl}=0.32-1.56, P=0.387$; and $\mathrm{RR}=0.36,95 \% \mathrm{Cl}=0.28-0.46, P<0.0001$; respectively). However, compared with the $\mathrm{PCl}$ group, the cerebral vascular accident was higher in the CABG group $(\mathrm{RR}=2.18,95 \% \mathrm{Cl}=1.43-3.33, P<0.0001)$. There was no publication bias in our study. CABG revascularization was associated with significantly lower long-term adverse clinical outcomes, except cerebral vascular accident, compared with $\mathrm{PCl}$ in patients with CAD and T2DM.

Systematic Review Registration: PROSPERO, identifier: CRD42020216014.

Keywords: coronary artery disease, type 2 diabetes mellitus, coronary artery bypass surgery, percutaneous coronary intervention, adverse clinical outcomes

\section{INTRODUCTION}

Cardiovascular disease is the leading cause of death in the world (1). According to World Health Organization, an estimated 17.3 million people died from cardiovascular diseases in 2008, accounting for $30 \%$ of the global deaths. It is predicted that by 2030, about 23.6 million people will die from cardiovascular diseases, mainly coronary artery disease (CAD) and stroke. Risk factors for CAD include smoking, unhealthy diet, inadequate daily exercise, overweight, or obesity $(1,2)$, which are also risk factors for diabetes (3). Diabetes poses as a major risk factor for the development of cardiovascular disease, which ultimately results in being the most common cause of death in those with diabetes (4). Diabetes is caused by insulin produced by the pancreas or tissue resistance in the terminal organs, manifested as hyperglycemia or elevated glycosylated hemoglobin A1C (3). Type 2 diabetes mellitus (T2DM) is the most common form of diabetes, accounting for $90-95 \%$ of the diagnosis of diabetes, and continues to grow rapidly around the world (5). Due to the few 
symptoms or signs of early T2DM, about half of the diabetics do not know that they have the disease. Symptoms are ignored before diagnosis and thus lead to diabetic complications, which can lead to cardiovascular diseases (6).

There is a strong correlation between CAD and T2DM $(7,8)$. Compared with the non-diabetic population, the progress of atherosclerosis in the diabetic group is earlier and more severe (9-11). Additionally, more complex coronary anatomy usually emerges in the diabetic group, which challenges the revascularization (12), whether coronary artery bypass grafting (CABG) or percutaneous coronary intervention (PCI). Cardiovascular deaths account for $52 \%$ of deaths in T2DM $(13,14)$. Moreover, T2DM increases the risk of cardiovascular death by two to six times (3). The mortality of diabetic patients after myocardial infarction is also significantly higher than that of non-diabetic patients $(15,16)$. Compared with nondiabetic patients of the same age group, the cardiovascular mortality of patients with no other traditional cardiovascular risk factors increased by 4.4 times $(17,18)$. Thereby, T2DM imperceptibly increases CAD mortality $(19,20)$. Although the mortality of CAD has been well-controlled with the development of interventional strategies (21), the prognosis of patients with $\mathrm{CAD}$ and T2DM is still very poor (22). One of the reasons is that diabetic patients have a worse prognosis following revascularization treatment (23). Simultaneously, patients with T2DM are at an increased risk of having a cardiovascular event, and more likely to have diffuse and multivessel vascular lesions $(24,25)$. Such patients are prone to a more rapid progression of atherosclerosis, significantly increasing the need for myocardial revascularization (26). Besides, patients with T2DM also have a worse prognosis following a coronary revascularization procedure (23). In this population, it may be difficult to choose the optimal revascularization strategy. The outcomes of different revascularization strategies have been extensively evaluated (27), but comparative data on the cause of mortality after these revascularization procedures are limited. A previous study suggests that, for patients with insulin-treated T2DM and multivessel ischemic heart disease, CABG is usually superior to PCI, leading to lower rates of all-cause mortality, major adverse cardiovascular, cerebrovascular events, and repeat revascularization in the long term, but the higher rate of stroke in the CABG group (28). It is necessary for further researches with a larger number of randomized patients to completely solve this issue. Therefore, we conducted this metaanalysis of randomized controlled trials (RCTs) to assess whether CABG can reduce adverse clinical outcomes in this special population and to determine the more suitable revascularization strategy.

\section{MATERIALS AND METHODS}

This study adhered to the PRISMA guidelines (29) and registered at PROSPERO with a unique identifier CRD42020216014.

Abbreviations: $\mathrm{CABG}$, coronary artery bypass grafting; CAD, coronary artery disease; CI, confidence interval; CVA, cerebralvascular accident; MI, myocardial infarction; PCI, percutaneous coronary intervention; RCT, Randomized Controlled Trial; RR, Risk ratio; T2DM, type 2 diabetes mellitus.

\section{Data Sources}

Two reviewers (BL and $\mathrm{XH}$ ) searched several electronic databases, including PubMed, Embase, and the Cochrane databases, along with RCTs from inception until July 2020, using the Medical Subject Heading and the keyword search terms: "coronary artery disease," "diabetes mellitus type 2," "percutaneous coronary intervention," and "coronary artery bypass grafting." To further enhance this search, the relevant abbreviations, such as CAD, T2DM, CABG, and PCI, were also conducted. References were also checked for potential RCTs and there was no language restriction.

\section{Selection Criteria}

We only included RCTs comparing long-term (more than 1 year) adverse clinical outcomes of different revascularization therapies, either CABG or PCI, in patients with CAD and T2DM. When the study was published repeatedly, the latest or complete data were included (30).

\section{Interventions}

Patients with T2DM who received insulin or medication were included in the study. These patients randomly underwent revascularization by either CABG or PCI. We evaluated the quality of the included studies based on the adequate description of treatment allocation and blinded outcome assessment.

\section{Outcomes and Definitions}

All-cause mortality during a long-term follow-up period was considered the primary outcome. Secondary outcomes for this study were composite cardiac mortality, recurrent myocardial infarction (MI), cerebralvascular accident (CVA), and repeat revascularization.

\section{Data Extraction and Quality Assessment}

Two reviewers (XH and $\mathrm{BL}$ ) independently assessed study eligibility and extracted data. We used a standardized data collection form to objectively evaluate each included study (30). The third reviewer (NG) solved the disagreement $(31,32)$. The extracted data included the year of publication, sample size, duration of follow-up, and the clinical outcomes (including all-cause mortality, recurrent myocardial infarction, CVA, and repeat revascularization). The bias risk was assessed using the components recommended by the Cochrane Collaboration guidelines, as described previously (31).

\section{Statistical Analysis}

This study was performed using STATA software (version 15, USA). Risk ratios (RRs) and 95\% confidence intervals (CIs) were used as summary statistics. Statistical heterogeneity was assessed for each outcome using the $I^{2}$ statistic. $I^{2}<25 \%$ is low heterogeneity, higher than $75 \%$ is high heterogeneity, and between the two is moderate heterogeneity, as described previously (31, 33-35). If $I^{2}$ was $<50 \%$, the fixed-effect model of Mantel-Haenszel was used to assess the overall estimate, otherwise, a random-effect model was conducted to calculate the pooled RRs (34). Moreover, sensitivity analysis (30), L'Abbe plot $(36,37)$, and Galbraith radial plot $(38)$ were conducted to assess 
Records identified through database searching $($ PubMed $=72$, Chochrance $=220$, Embase $=81)$

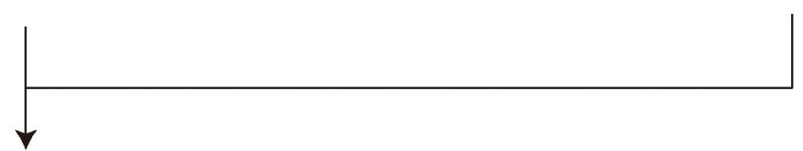

Additional records identified through other source

$$
(\mathrm{n}=0)
$$

Records after duplicates removed

$$
(\mathrm{n}=301)
$$

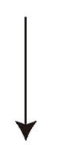

Records pulled following title/abstract screened

$$
(\mathrm{n}=301)
$$

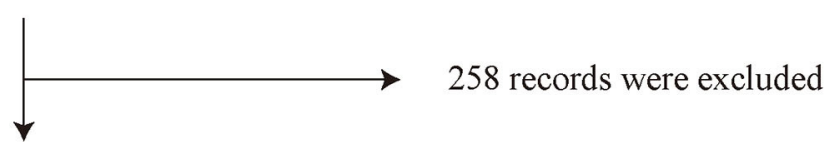

Full-text articles assessed for eligibility

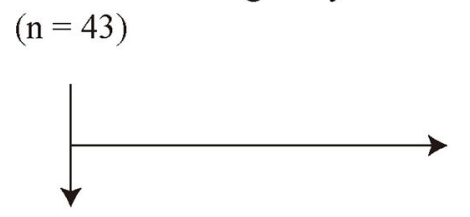

Full-text articles excluded with reasons:

1. Guidelines, observational studies and reviews $(n=15)$

2. Inconsistent study design $(n=9)$

$\frac{7}{\frac{0}{0}}$

3. Non RCTs $(n=6)$

Studies included in qualitative synthesis

4. Irrelevance $(n=6)$

$$
(n=7)
$$

FIGURE 1 | Flow diagram.

heterogeneity. Lastly, the funnel plot and Begg's and Egger's tests were implemented to assess the publication bias.

\section{RESULTS}

\section{Characteristics of Included Studies}

Our search identified 373 articles, ultimately six RCTs [ARTS (39), BARI 2D (40), FREEDOM (41)/FREEDOM Follow-On (42), MASS II (43), SYNTAX (44), and VACARDS (45)] were included in this study. The flow diagram of this study selection is represented in Figure 1. A total of 4,028 patients underwent revascularization, among them 2,262 patients were assigned to the PCI group and 1,766 patients were assigned to the CABG group. Most trials were international RCTs. The characteristics of the included studies are presented in Table $\mathbf{1}$, and the baseline clinical characteristics are shown in Supplementary Table 1. Since FREEDOM Follow-On (42) was the longer follow-up data of FREEDOM (41) and only reported all-cause mortality, we used data from FREEDOM Follow-On (42) to analyze allcause mortality.

\section{Primary Outcome}

All included studies reported all-cause mortality. The all-cause mortality of CABG was significantly lower than that of PCI in patients with CAD and T2DM $(\mathrm{RR}=0.74,95 \% \mathrm{CI}=0.56-0.98$, $P=0.037)$, albeit with moderate heterogeneity $\left(I^{2}=59.6 \%, P_{\mathrm{h}}\right.$ $=0.030)$ (Figure 2).

\section{Heterogeneity and Publication Bias}

Further performances of the LAbbe plot (Figure 3A) and Galbraith Radial plot (Figure 3B) indicated that there was a possible heterogeneity in this pooled result. Therefore, a search for heterogeneous sources was needed. Sensitivity analysis was performed to evaluate individual study's influence 
TABLE 1 | Baseline patient characteristics.

\begin{tabular}{|c|c|c|c|c|c|c|c|}
\hline Trials & Year & Numbers (CABG/PCI) (n) & Ages (years) & Males (\%) & Outcomes & Follow-up (year) & References \\
\hline ARTS & 2001 & $96 / 112$ & $62.6 / 62.4$ & $148(71.12 \%)$ & $a, b, c, d$ & 1 & (39) \\
\hline BARI 2D & 2009 & $378 / 798$ & Not applicable & Not applicable & $\mathrm{a}, \mathrm{e}$ & 5 & $(40)$ \\
\hline FREEDOM & 2014 & $277 / 325$ & $61.9 \pm 9.2 / 63.2 \pm 9.2$ & 369 (61.30\%) & $a, b, d, f$ & 1,5 & $(41)$ \\
\hline FREEDOM Follow-On & 2019 & $947 / 953$ & 63.3 & $1356(71.37 \%)$ & a & 8 & $(42)$ \\
\hline MASS ॥ & 2013 & $80 / 64$ & $59 \pm 8 / 61 \pm 9$ & 128 (88.89\%) & $\mathrm{a}, \mathrm{e}$ & 10 & (43) \\
\hline SYNTAX & 2013 & $221 / 231$ & $65.4 \pm 9.2$ & 321 (71.02\%) & $a, b, d, e, f$ & 5 & $(44)$ \\
\hline VACARDS & 2013 & $97 / 101$ & $62.1 \pm 7.4 / 62.7 \pm 7.1$ & 196 (98.99\%) & $a, b$ & 1,2 & (45) \\
\hline
\end{tabular}

a, all-cause mortality; b, myocardial infarction; c, cerebralvascular accident; $d$, repeat revascularazition; e, cardiac mortality; $f$, stroke.

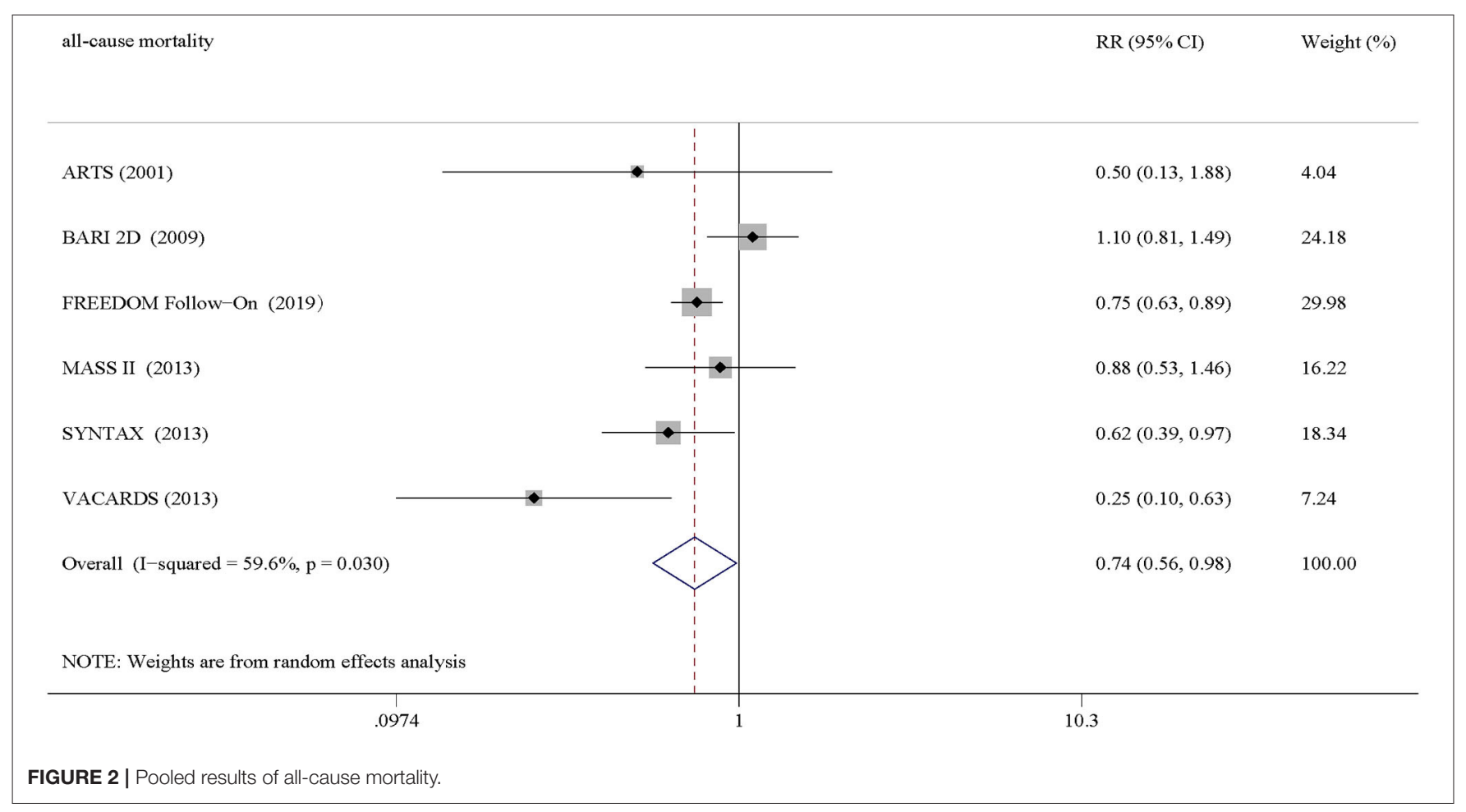

on the pooled results to verify the consistency of the metaanalysis consequences. The results revealed that FREEDOM Follow-On (42) might have a greater impact on heterogeneity, which disclosed that they may be the source of heterogeneity (Figure 3C). However, when FREEDOM Follow-On was omitted, the pooled results did not change $(\mathrm{RR}=0.69,95 \%$ $\mathrm{CI}=0.44-1.07$ ) (Figure 3C). Funnel plot analysis showed that there was no statistical evidence of publication bias of all-cause mortality in this study (Figure 3D). Moreover, Begg's and Egger's tests were applied to confirm this $\left(P_{\text {Begg's test }}=0.707\right.$ and $P_{\text {Egger's test }}=0.427$, respectively) (Figures 3E, F).

\section{Secondary Outcomes}

A total of three trials reported cardiac mortality. We found that cardiac mortality of CABG was lower than that of PCI in patients with $\mathrm{CAD}$ and $\mathrm{T} 2 \mathrm{DM}$, with no statistical difference $(\mathrm{RR}=0.79$, 95\% CI $=0.40-1.53, P=0.479)$ (Figure 4A). Data synthesis of four trials showed that recurrent $\mathrm{MI}$ was more favorable in the CABG group than PCI group $(\mathrm{RR}=0.70,95 \% \mathrm{CI}=0.32-1.56$, $P=0.387$ ) (Figure 4B). Moreover, patients in the PCI group had more CVA than those in the CABG group ( $\mathrm{RR}=2.18,95 \% \mathrm{CI}$ $=1.43-3.33, P<0.0001$ ) (Figure 4C), whereas, patients in the CABG group had a lower repeat revascularization than those in the PCI group $(\mathrm{RR}=0.36,95 \% \mathrm{CI}=0.28-0.46, P<0.0001)$ (Figure 4D).

\section{DISCUSSION}

Previous studies have compared the effects of CABG with PCI on health-related quality of life in patients with CAD with multivessel disease. In general, CABG provides better relief of central colic in the first 1-3 years after initial revascularization than PCI (46). However, with the advancement of revascularization technology, the benefits provided by CABG 


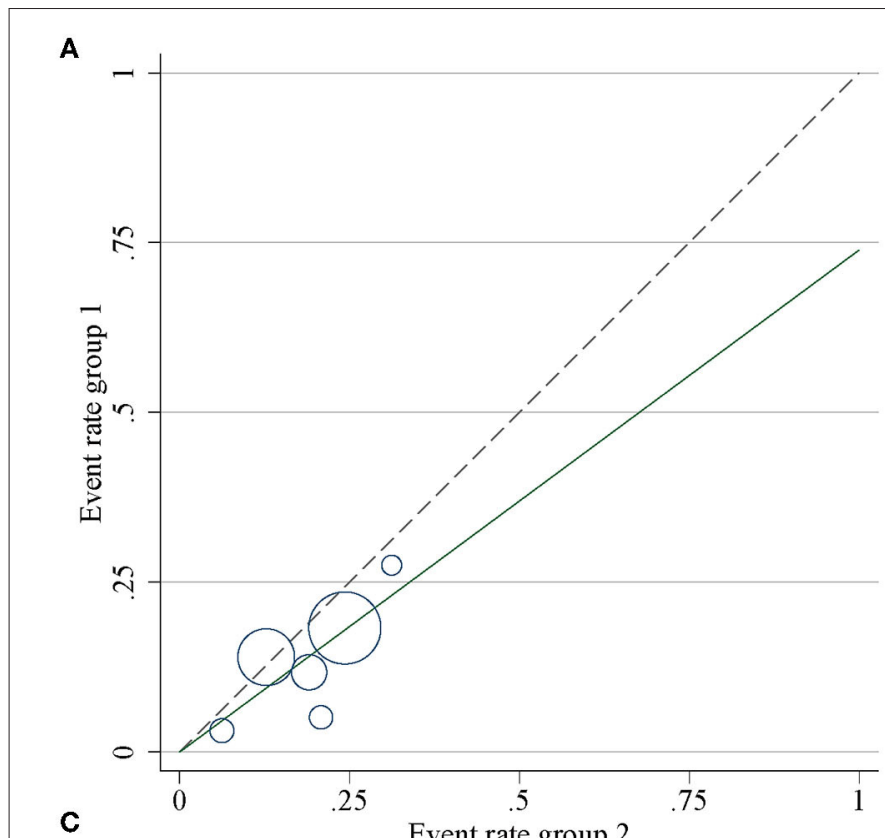

$\mathbf{B}$

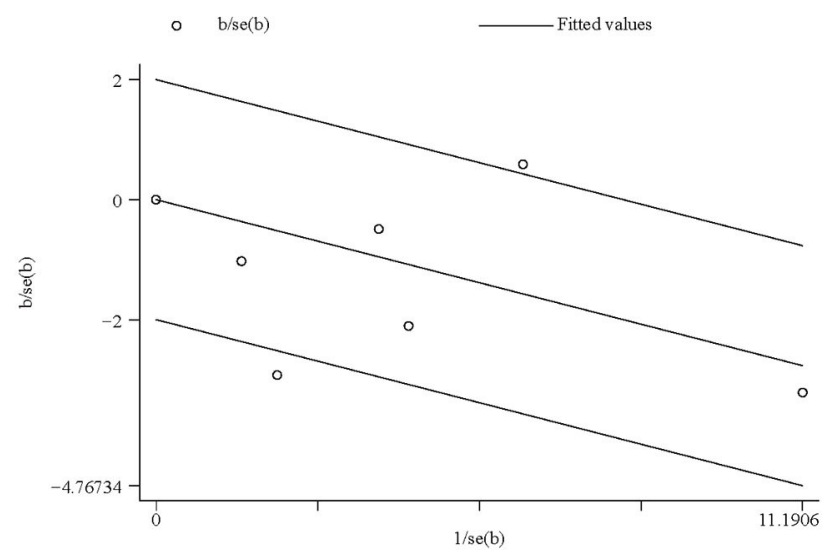

Event rate group 2
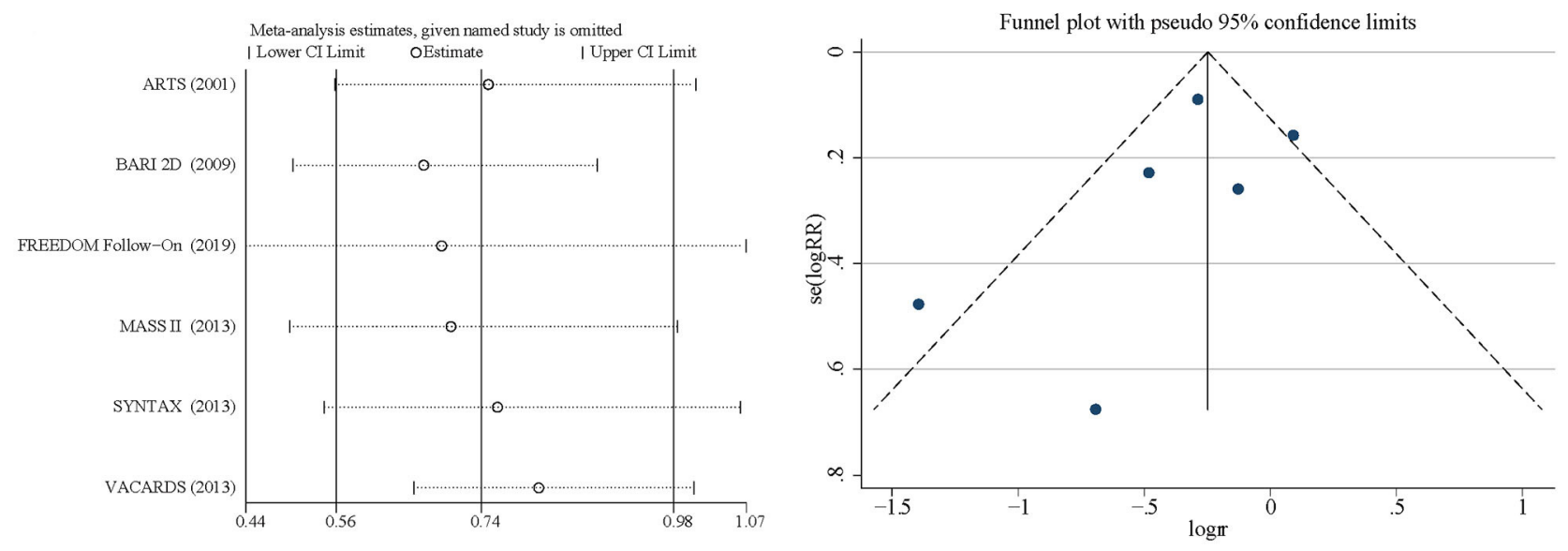

E
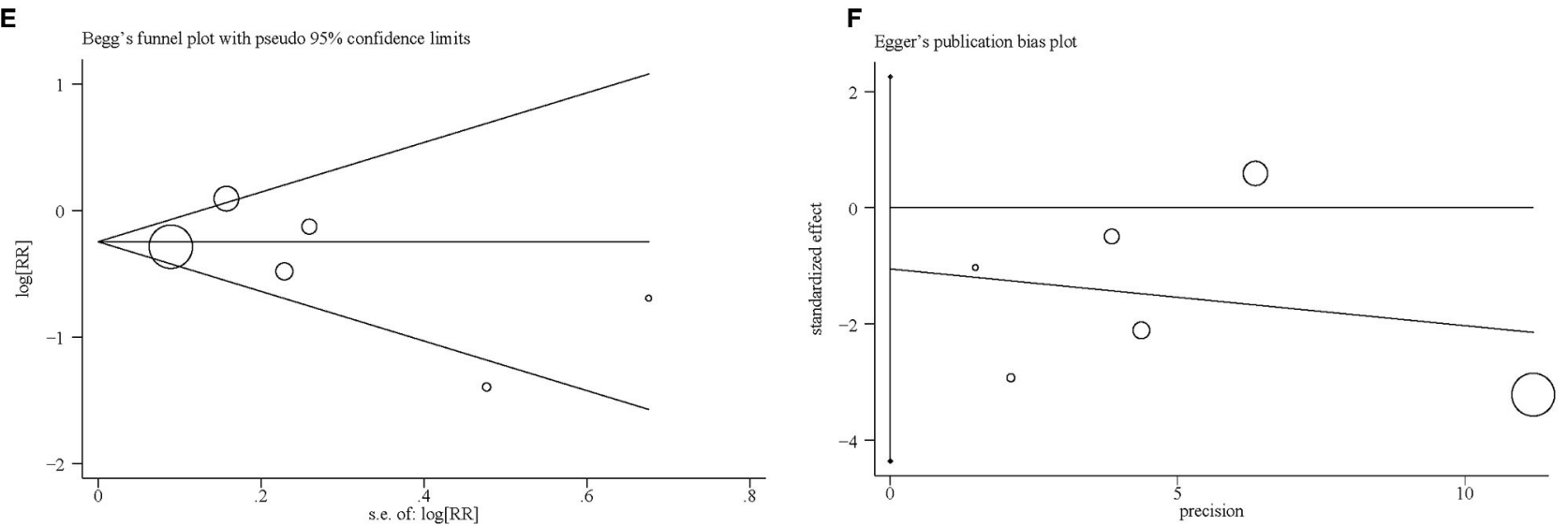

FIGURE 3 | Heterogeneity and sensitivity analysis. (A) L'Abbe plot. (B) Galbraith Radial plot. (C) Sensitivity analysis. (D) Funnel plot. (E) Begg's plot. (F) Egger's plot.

compared with PCI are gradually reduced, but it has a higher rate of stroke. Recent studies comparing CABG with PCI found significantly lower mortality rates among patients with
T2DM revascularized by CABG compared with those patients revascularized by $\mathrm{PCI}$, but a significantly higher risk of stroke in these studies, with no statistical significance $(28,47,48)$. 


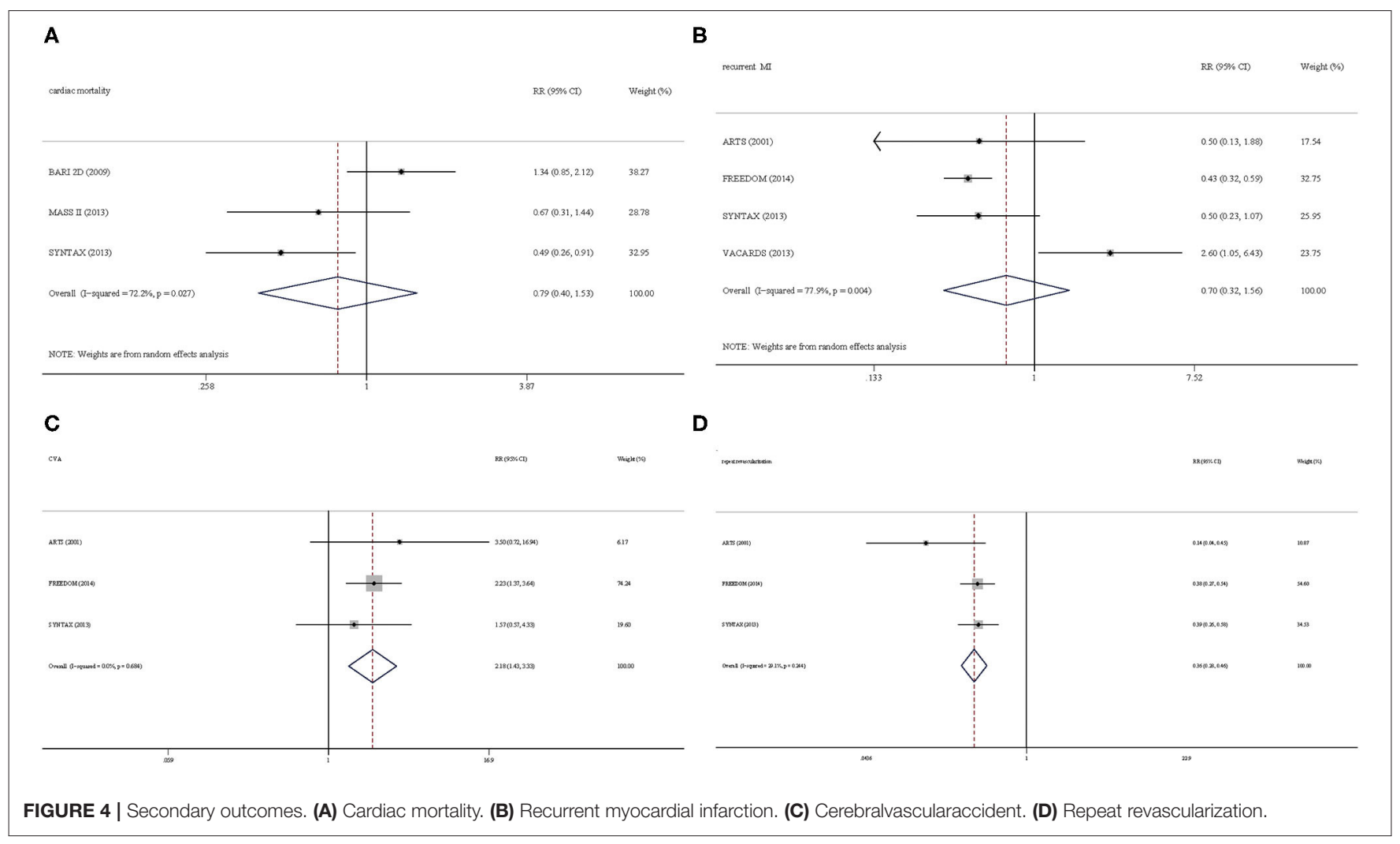

Besides, Gargiolo et al. compared the 5 years clinical outcomes and showed that the rate of repeated revascularization was significantly increased in the PCI group, but there was no statistical difference in mortality, MI, and stroke between CABG and PCI (49). These studies showed that data regarding the long-term adverse clinical outcomes in patients with T2DM revascularized by either CABG or PCI are still controversial (50). So, we aim to solve this issue in our present study.

In this study, we compared the effects of two different revascularization strategies, $\mathrm{CABG}$ and $\mathrm{PCI}$, on CAD patients with T2DM. Our results showed that an all-cause mortality, cardiac mortality, recurrent $\mathrm{MI}$, and repeat revascularization were lower in the CABG group when compared with the PCI group, whereas CVA was higher in the CABG group compared with the PCI group, with a statistical significance in the present study. Therefore, CABG is the first choice for most patients with CAD patients with T2DM. However, longer-term followup and data from more trials will be needed to provide a more precise comparison of the efficacy of these two revascularization strategies for this particular population. CARDia is the first RCT of coronary revascularization in diabetic patients, but the 1year results did not show that PCI is non-inferior to CABG (51). In the total 510 patients, $4.90 \%$ were type 1 diabetes mellitus (17 and eight cases in the CABG group and PCI group, respectively). Although the number of cases is small, we can only approximately infer that the results of this trial can be applied to T2DM patients, and we have not included the analysis of CARDia in our study. It is not a unique instance, but has its counterpart. We also cannot extract the data of CAD patients with T2DM in SOS (the Stent or Surgery trial) (52), ERACI II (Argentine randomized study: Coronary angioplasty with stenting vs. coronary bypass surgery in patients with multiplevessel disease) (53), and ASAN-MAIN (ASAN medical center-left MAIN revascularization) (54).

For the treatment of unprotected left main CAD, PCI with stent implantation showed similar long-term mortality and rates of death, Q-wave MI, or stroke. However, stenting, even with drug-eluting stents, was associated with higher rates of repeat revascularization than was CABG. In the Intermountain Heart Registry of patients undergoing revascularization for multivessel CAD, a long-term benefit was found, in relation to both death and major adverse cardiovascular events, for CABG over PCI regardless of diabetic status (55). However, in ARTS-II (arterial revascularization therapies study-part II) at 3-year follow-up, PCI using sirolimus-eluting stents for patients with multivessel CAD appears to be a valuable alternative to CABG for both diabetic and non-diabetic patients (56), and in the 5-year followup, PCI using sirolimus-eluting stents had an approximately safer record and higher MACCE rate compared with CABG (57). In addition to multivessel $\mathrm{CAD}$, recent observational and subgroup analyses suggest that CABG might be the preferential method of revascularization for patients with T2DM and MVD, also in the non-ST-segment elevation acute coronary syndrome setting (58). There are many uncertainties regarding the best revascularization strategy in the multivessel CAD or acute scenario, and dedicated randomized clinical trials are needed. 
There existed several limitations in our work that need to be optimized in the future. First, to assess the long-term followup events between CABG and PCI in patients with CAD and T2DM, we only included six RCTs after strict inclusion and exclusion criteria, indicating we may be missing some important evidence from observational studies. Moreover, differences in procedural aspects, post-procedural management, and followup protocol may have existed between the included trials. In addition, our primary outcome, the all-cause mortality, which is the most comprehensive and unbiased endpoint for myocardial revascularization trials $(59,60)$, was reported by all the trials. However, our secondary outcomes were not reported by several trials. Fourth, since we cannot obtain the drug use of the included patients, we cannot analyze whether the drug use, especially the hypoglycemic drugs that gradually show cardiovascular benefits (61-64), brings additional benefits in different revascularization strategies. Fifth, the follow-up in each study was different (Table 1), FREEDOM Follow-On and MASS II were followed up for more than 7 years, whereas ARTS and VACARDS were followed up for $<3$ years. Longer follow-up may show more outcome events, which need to be verified in more carefully designed trials. Finally, although most of the included RCTs were international studies, background heterogeneity cannot be avoided.

\section{CONCLUSIONS}

Patients with CAD and T2DM undergoing CABG surgery have lower all-cause mortality, cardiac mortality, recurrent $\mathrm{MI}$, and repeat revascularization, but higher CVA than those undergoing PCI. This information may be useful in counseling patients with T2DM requiring appropriate coronary revascularization; however, more evaluations in adequately powered large trials are required to further confirm the clinical benefit of this strategy.

\section{REFERENCES}

1. Balakumar P, Maung-U K, Jagadeesh G. Prevalence and prevention of cardiovascular disease and diabetes mellitus. Pharmacol Res. (2016) 113(Pt A):600-9. doi: 10.1016/j.phrs.2016.09.040

2. Strain WD, Paldánius PM. Diabetes, cardiovascular disease and the microcirculation. Cardiovasc Diabetol. (2018) 17:57. doi: 10.1186/s12933-018-0703-2

3. Glovaci D, Fan W, Wong ND. Epidemiology of diabetes mellitus and cardiovascular disease. Curr Cardiol Rep. (2019) 21:21. doi: 10.1007/s11886-019-1107-y

4. Benjamin EJ, Virani SS, Callaway CW, Chamberlain AM, Chang AR, Cheng S, et al. Heart disease and stroke statistics-2018 update: a report from the American Heart Association. Circulation. (2018) 137:e67492. doi: 10.1161/CIR.0000000000000558

5. Mayer-Davis EJ, Lawrence JM, Dabelea D, Divers J, Isom S, Dolan L, et al. Incidence trends of type 1 and type 2 diabetes among youths, 2002-2012. N Engl J Med. (2017) 376:1419-29. doi: 10.1056/NEJMoa1610187

6. Rawshani A, Rawshani A, Franzén S, Eliasson B, Svensson A-M, Miftaraj M, et al. Mortality and Cardiovascular disease in type 1 and type 2 diabetes. $N$ Engl J Med. (2017) 376:1407-18. doi: 10.1056/NEJMoa1608664

7. Liang B, Zhao Y-X, Zhang X-X, Liao H-L, Gu N. Reappraisal on pharmacological and mechanical treatments of heart failure. Cardiovasc Diabetol. (2020) 19:55. doi: 10.1186/s12933-020-01024-5

\section{DATA AVAILABILITY STATEMENT}

The original contributions presented in the study are included in the article/Supplementary Material, further inquiries can be directed to the corresponding author.

\section{AUTHOR CONTRIBUTIONS}

BL and NG conceived, designed, or planned the idea. BL drafted the manuscript. NG revised the manuscript. All authors collected, analyzed, interpreted data, and read and approved the final manuscript.

\section{FUNDING}

This study was partly funded by Research and Practice Innovation Plan for Postgraduates of Jiangsu, China (KYCX21_1641), National Natural Science Foundation of China (81774229), Jiangsu Leading Talent Project of Traditional Chinese Medicine (Jiangsu TCM 2018 No. 4), and Jiangsu Universities Nursing Advantage Discipline Project (2019YSHL095).

\section{ACKNOWLEDGMENTS}

The authors thank all relevant published studies and individuals involved in CAD and T2DM.

\section{SUPPLEMENTARY MATERIAL}

The Supplementary Material for this article can be found online at: https://www.frontiersin.org/articles/10.3389/fcvm. 2021.738620/full\#supplementary-material

8. Aune SK, Byrkjeland R, Solheim S, Arnesen H, Trøseid M, Awoyemi $A$, et al. Gut related inflammation and cardiorespiratory fitness in patients with CAD and type 2 diabetes: a sub-study of a randomized controlled trial on exercise training. Diabetol Metab Syndr. (2021) 13:36. doi: 10.1186/s13098-021-00655-2

9. Patsouras A, Farmaki P, Garmpi A, Damaskos C, Garmpis N, Mantas $\mathrm{D}$, et al. Screening and risk assessment of coronary artery disease in patients with type 2 diabetes: an updated review. In vivo. (2019) 33:103949. doi: 10.21873/invivo.11572

10. Poznyak A, Grechko AV, Poggio P, Myasoedova VA, Alfieri V, Orekhov AN. The diabetes mellitus-atherosclerosis connection: the role of lipid and glucose metabolism and chronic inflammation. Int J Mol Sci. (2020) 21:1835. doi: 10.3390/ijms21051835

11. La Sala L, Prattichizzo F, Ceriello A. The link between diabetes and atherosclerosis. Eur J Prev Cardiol. (2019) 26(2_suppl):1524. doi: $10.1177 / 2047487319878373$

12. Godoy LC, Ko DT, Rao V, Farkouh ME. The role of coronary artery bypass surgery versus percutaneous intervention in patients with diabetes and coronary artery disease. Prog Cardiovasc Dis. (2019) 62:358-63. doi: 10.1016/j.pcad.2019.07.004

13. Al-Jarallah M, Rajan R, Al-Zakwani I, Dashti R, Bulbanat B, Ridha M, et al. Impact of diabetes on mortality and rehospitalization in acute heart failure patients stratified by ejection fraction. ESC Heart Fail. (2020) 7:297305. doi: $10.1002 /$ ehf2.12538 
14. Kang SM, Jung HS, Kwon MJ, Lee SH, Park JH. Effects of anagliptin on the stress induced accelerated senescence of human umbilical vein endothelial cells. Ann Transl Med. (2021) 9:750. doi: 10.21037/atm-21-393

15. Jeong M-J, Kwon H, Jung CH, Kwon SU, Kim M-J, Han Y, et al. Comparison of outcomes after carotid endarterectomy between type 2 diabetic and nondiabetic patients with significant carotid stenosis. Cardiovasc Diabetol. (2019) 18:41. doi: 10.1186/s12933-019-0848-7

16. Icks A, Claessen H, Kirchberger I, Heier M, Peters A, Trentinaglia I, et al. Mortality after first myocardial infarction in diabetic and non-diabetic people between 1985 and 2009. The MONICA/KORA registry. Eur J Epidemiol. (2014) 29:899-909. doi: 10.1007/s10654-014-9964-6

17. Chichareon P, Modolo R, Kogame N, Takahashi K, Chang C-C, Tomaniak $\mathrm{M}$, et al. Association of diabetes with outcomes in patients undergoing contemporary percutaneous coronary intervention: pre-specified subgroup analysis from the randomized GLOBAL LEADERS study. Atherosclerosis. (2020) 295:45-53. doi: 10.1016/j.atherosclerosis.2020.01.002

18. Ding Q, Spatz ES, Lipska KJ, Lin H, Spertus JA, Dreyer RP, et al. Newly diagnosed diabetes and outcomes after acute myocardial infarction in young adults. Heart (British Cardiac Society). (2021) 107:657-66. doi: 10.1136/heartjnl-2020-317101

19. Wong Y-K, Cheung CYY, Tang CS, Hai JSH, Lee C-H, Lau K-K, et al. High-sensitivity troponin I and B-type natriuretic peptide biomarkers for prediction of cardiovascular events in patients with coronary artery disease with and without diabetes mellitus. Cardiovasc Diabetol. (2019) 18:171. doi: 10.1186/s12933-019-0974-2

20. Guo L, Wang J, Ding H, Meng S, Zhang X, Lv H, et al. Long-term outcomes of medical therapy versus successful recanalisation for coronary chronic total occlusions in patients with and without type 2 diabetes mellitus. Cardiovasc Diabetol. (2020) 19:100. doi: 10.1186/s12933-020-01087-4

21. Liang $\mathrm{B}, \mathrm{Qu} \mathrm{Y}$, Zhao Q-F, Gu N. Guanxin V for coronary artery disease: a retrospective study. Biomed Pharmacother. (2020) 128:110280. doi: 10.1016/j.biopha.2020.110280

22. Yue Z, Li L, Fu H, Yin Y, Du B, Wang F, et al. Effect of dapagliflozin on diabetic patients with cardiovascular disease via MAPK signalling pathway. J Cell Mol Med. (2021) 25:7500-12. doi: 10.1111/jcmm.16786

23. Investigators $\mathrm{B}$. The final 10-year follow-up results from the BARI randomized trial. J Am Coll Cardiol. (2007) 49:1600-6. Epub 2007/04/17. doi: 10.1016/j.jacc.2006.11.048

24. Dai X, Luo Z-C, Zhai L, Zhao W-P, Huang F. Reassessing coronary artery bypass surgery versus percutaneous coronary intervention in patients with type 2 diabetes mellitus: a brief updated analytical report (2015-2017). Diabetes Ther. (2018) 9:2163-71. doi: 10.1007/s13300-018-0504-3

25. Kogan A, Ram E, Levin S, Fisman EZ, Tenenbaum A, Raanani E, et al. Impact of type 2 diabetes mellitus on short- and long-term mortality after coronary artery bypass surgery. Cardiovasc Diabetol. (2018) 17:151. doi: 10.1186/s12933-018-0796-7

26. Wang $\mathrm{H}$, Wang $\mathrm{H}$, Wei $\mathrm{Y}, \mathrm{Li} \mathrm{X}$, Jhummun V, Ahmed MA. Ten-year outcomes of percutaneous coronary intervention versus coronary artery bypass grafting for patients with type 2 diabetes mellitus suffering from left main coronary disease: a meta-analysis. Diabetes Ther. (2021) 12:104154. doi: 10.1007/s13300-021-01025-x

27. Xie Q, Huang J, Zhu K, Chen Q. Percutaneous coronary intervention versus coronary artery bypass grafting in patients with coronary heart disease and type 2 diabetes mellitus: cumulative meta-analysis. Clin Cardiol. (2021) 44:899-906. doi: 10.1002/clc.23613

28. Bundhun PK, Wu ZJ, Chen MH. Coronary artery bypass surgery compared with percutaneous coronary interventions in patients with insulin-treated type 2 diabetes mellitus: a systematic review and metaanalysis of 6 randomized controlled trials. Cardiovasc Diabetol. (2016) 15:2. doi: 10.1186/s12933-015-0323-Z

29. Liberati A, Altman DG, Tetzlaff J, Mulrow C, Gøtzsche PC, Ioannidis JPA, et al. The PRISMA statement for reporting systematic reviews and meta-analyses of studies that evaluate health care interventions: explanation and elaboration. Epidemiol Biostat Public Health. (2009) 6:e134. doi: 10.1016/j.jclinepi.2009.06.006

30. Wang X-F, Liang B, Chen C, Zeng D-X, Zhao Y-X, Su N, et al. Long Intergenic Non-protein Coding RNA 511 in Cancers. Front Genet. (2020) 11:667. doi: 10.3389/fgene.2020.00667
31. Liang B, Zhao L-Z, Liao H-L, Gu N. Rivaroxaban for cancer-associated venous thromboembolism: a systematic review and meta-analysis protocol. Medicine. (2019) 98:e18087. doi: 10.1097/MD.0000000000018087

32. Liang $B$, Liang $Y$, Zhao L-Z, Zhao Y-X, Gu N. Rivaroxaban for cancer-associated venous thromboembolism. Sci Prog. (2021) 104:368504211012160. doi: 10.1177/00368504211012160

33. JP H, SG T, JJ D, DG A. Measuring inconsistency in meta-analyses. BMJ. (2003) 327:557-60. doi: 10.1136/bmj.327.7414.557

34. Wang X-F, Liang B, Zeng D-X, Lei W, Chen C, Chen Y-B, et al. The roles of MASPIN expression and subcellular localization in non-small cell lung cancer. Biosci Rep. (2020) 40:BSR20200743. doi: 10.1042/BSR20200743

35. Liang B, Li S-Y, Gong H-Z, Wang L-X, Lu J, Zhao Y-X, et al. Clinicopathological and prognostic roles of STAT3 and its phosphorylation in glioma. Dis Markers. (2020) 2020:8833885. doi: 10.1155/2020/8833885

36. Bahlool SA. Use of L'Abbe plot in meta-analysis. $\mathrm{Br} J$ Anaesth. (2011) 107:104. doi: 10.1093/bja/aer174

37. Ho KM, Tan JA. Use of L'Abbé and pooled calibration plots to assess the relationship between severity of illness and effectiveness in studies of corticosteroids for severe sepsis. Br J Anaesth. (2011) 106:52836. doi: $10.1093 / \mathrm{bja} / \mathrm{aeq} 417$

38. Huang H, Xu S, Huang F, Wang X, Chen Y, Xu Z. A Meta-analysis of efficacy and safety of infliximab for prevention of postoperative recurrence in patients with Crohn's disease. BioMed Res Int. (2018) 2018:2615978. doi: 10.1155/2018/2615978

39. Abizaid A, Costa MA, Centemero M, Abizaid AS, Legrand VM, Limet RV, et al. Clinical and economic impact of diabetes mellitus on percutaneous and surgical treatment of multivessel coronary disease patients: insights from the Arterial Revascularization Therapy Study (ARTS) trial. Circulation. (2001) 104:533-8. doi: 10.1161/hc3101.093700

40. Chaitman BR, Hardison RM, Adler D, Gebhart S, Grogan M, Ocampo S, et al. The Bypass Angioplasty Revascularization Investigation 2 Diabetes randomized trial of different treatment strategies in type 2 diabetes mellitus with stable ischemic heart disease: impact of treatment strategy on cardiac mortality and myocardial infarction. Circulation. (2009) 120:252940. doi: 10.1161/CIRCULATIONAHA.109.913111

41. Dangas GD, Farkouh ME, Sleeper LA, Yang M, Schoos MM, Macaya C, et al. Long-term outcome of PCI versus CABG in insulin and non-insulin-treated diabetic patients: results from the FREEDOM trial. J Am Coll Cardiol. (2014) 64:1189-97. doi: 10.1016/j.jacc.2014.06.1182

42. Farkouh ME, Domanski M, Dangas GD, Godoy LC, Mack MJ, Siami FS, et al. Long-term survival following multivessel revascularization in patients with diabetes: the FREEDOM follow-on study. J Am Coll Cardiol. (2019) 73:629-38. doi: 10.1016/j.jacc.2018.11.001

43. Lima EG, Hueb W, Garcia RM, Pereira AC, Soares PR, Favarato D, et al. Impact of diabetes on 10-year outcomes of patients with multivessel coronary artery disease in the Medicine, Angioplasty, or Surgery Study II (MASS II) trial. Am Heart J. (2013) 166:250-7. doi: 10.1016/j.ahj.2013.04.017

44. Kappetein AP, Head SJ, Morice MC, Banning AP, Serruys PW, Mohr FW, et al. Treatment of complex coronary artery disease in patients with diabetes: 5-year results comparing outcomes of bypass surgery and percutaneous coronary intervention in the SYNTAX trial. Eur J Cardio-Thor Surg. (2013) 43:100613. doi: 10.1093/ejcts/ezt017

45. Kamalesh M, Sharp TG, Tang XC, Shunk K, Ward HB, Walsh J, et al. Percutaneous coronary intervention versus coronary bypass surgery in United States veterans with diabetes. J Am Coll Cardiol. (2013) 61:80816. doi: 10.1016/j.jacc.2012.11.044

46. Hoffman SN, TenBrook JA, Wolf MP, Pauker SG, Salem DN, Wong JB. A meta-analysis of randomized controlled trials comparing coronary artery bypass graft with percutaneous transluminal coronary angioplasty: one- to eight-year outcomes. J Am Coll Cardiol. (2003) 41:1293304. doi: 10.1016/S0735-1097(03)00157-8

47. Smit Y, Vlayen J, Koppenaal H, Eefting F, Kappetein AP, Mariani MA. Percutaneous coronary invervention versus coronary artery bypass grafting: a meta-analysis. J Thor Cardiovas Surg. (2015) 149:831-8.e113. doi: $10.1016 /$ j.jtcvs.2014.10.112

48. Verma S, Farkouh ME, Yanagawa B, Fitchett DH, Ahsan MR, Ruel M, et al. Comparison of coronary artery bypass surgery and percutaneous coronary intervention in patients with diabetes: a meta-analysis of 
randomised controlled trials. Lancet Diabetes Endocrinol 1:317-28. doi: 10.1016/S2213-8587(13)70089-5

49. Gargiulo G, Tamburino C, Capodanno D. Five-year outcomes of percutaneous coronary intervention versus coronary artery bypass graft surgery in patients with left main coronary artery disease: an updated meta-analysis of randomized trials and adjusted observational studies. Int J Cardiol. (2015) 195:79-81. doi: 10.1016/j.ijcard.2015.05.136

50. Yamamoto K, Shiomi H, Morimoto $T$, Kadota K, Tada T, Takeji $\mathrm{Y}$, et al. Percutaneous coronary intervention versus coronary artery bypass graftinge among patients with unprotected left main coronary artery disease in the new-generation drug-eluting stents era (From the CREDO-Kyoto PCI/CABG registry cohort-3). Am J Cardiol. (2021) 145:47-57. doi: 10.1016/j.amjcard.2020.12.078

51. Kapur A, Hall RJ, Malik IS, Qureshi AC, Butts J, de Belder M, et al. Randomized comparison of percutaneous coronary intervention with coronary artery bypass grafting in diabetic patients. 1-year results of the CARDia (Coronary Artery Revascularization in Diabetes) trial. J Am Coll Cardiol. (2010) 55:432-40. doi: 10.1016/j.jacc.2009.10.014

52. Investigators S. Coronary artery bypass surgery versus percutaneous coronary intervention with stent implantation in patients with multivessel coronary artery disease (the Stent or Surgery trial): a randomised controlled trial. Lancet. (2002) 360:965-70. doi: 10.1016/S0140-6736(02)11 078-6

53. Rodriguez A, Bernardi V, Navia J, Baldi J, Grinfeld L, Martinez J, et al. Argentine randomized study: coronary angioplasty with stenting versus coronary bypass surgery in patients with multiple-vessel disease (ERACI II): 30-day and one-year follow-up results. ERACI II Investigators. J Am Coll Cardiol. (2001) 37:51-8. doi: 10.1016/S0735-1097(00)01052-4

54. Park D-W, Kim Y-H, Yun S-C, Lee J-Y, Kim W-J, Kang S-J, et al. Long-term outcomes after stenting versus coronary artery bypass grafting for unprotected left main coronary artery disease: 10-year results of bare-metal stents and 5year results of drug-eluting stents from the ASAN-MAIN (ASAN Medical Center-Left MAIN Revascularization) Registry. J Am Coll Cardiol. (2010) 56:1366-75. doi: 10.1016/j.jacc.2010.03.097

55. Bair TL, Muhlestein JB, May HT, Meredith KG, Horne BD, Pearson $\mathrm{RR}$, et al. Surgical revascularization is associated with improved longterm outcomes compared with percutaneous stenting in most subgroups of patients with multivessel coronary artery disease: results from the Intermountain Heart Registry. Circulation. (2007) 116(11 Suppl.):I226I31. doi: 10.1161/CIRCULATIONAHA.106.681346

56. Daemen J, Kuck KH, Macaya C, LeGrand V, Vrolix M, Carrie D, et al. Multivessel coronary revascularization in patients with and without diabetes mellitus: 3-year follow-up of the ARTS-II (Arterial Revascularization Therapies Study-Part II) trial. J Am Coll Cardiol. (2008) 52:1957-67. doi: 10.1016/j.jacc.2008.09.010

57. Serruys PW, Onuma Y, Garg S, Vranckx P, De Bruyne B, Morice M-C, et al. 5-year clinical outcomes of the ARTS II (Arterial Revascularization Therapies Study II) of the sirolimus-eluting stent in the treatment of patients with multivessel de novo coronary artery lesions. J Am Coll Cardiol. (2010) 55:1093-101. doi: 10.1016/j.jacc.2009.11.049

58. Godoy LC, Lawler PR, Farkouh ME, Hersen B, Nicolau JC, Rao V. Urgent revascularization strategies in patients with diabetes mellitus and acute coronary syndrome. Can J Cardiol. (2019) 35:993-1001. doi: 10.1016/j.cjca.2019.03.010

59. Gaudino M, Hameed I, Farkouh ME, Rahouma M, Naik A, Robinson $\mathrm{NB}$, et al. Overall and cause-specific mortality in randomized clinical trials comparing percutaneous interventions with coronary bypass surgery: a meta-analysis. JAMA Internal Med. (2020) 180:1638-46. doi: 10.1001/jamainternmed.2020.4748

60. Nanna MG, Newby LK. In coronary artery disease, PCI increases all-cause and cause-specific mortality compared with CABG. Ann Intern Med. (2021) 174:JC27. doi: 10.7326/ACPJ202103160-027

61. Santos-Gallego CG, Vargas-Delgado AP, Requena-Ibanez JA, Garcia-Ropero A, Mancini D, Pinney S, et al. Randomized trial of empagliflozin in nondiabetic patients with heart failure and reduced ejection fraction. J Am Coll Cardiol. (2021) 77:243-55. doi: 10.1016/j.jacc.2020.11.008

62. Petrie MC, Verma S, Docherty KF, Inzucchi SE, Anand I, Belohlávek J, et al. Effect of dapagliflozin on worsening heart failure and cardiovascular death in patients with heart failure with and without diabetes. JAMA. (2020) 323:1353-68. doi: 10.1001/jama.2020.1906

63. Tanaka A, Hisauchi I, Taguchi I, Sezai A, Toyoda S, Tomiyama H, et al. Effects of canagliflozin in patients with type 2 diabetes and chronic heart failure: a randomized trial (CANDLE). ESC Heart Fail. (2020) 7:158594. doi: 10.1002/ehf2.12707

64. Cannon CP, Pratley R, Dagogo-Jack S, Mancuso J, Huyck S, Masiukiewicz U, et al. Cardiovascular outcomes with ertugliflozin in type 2 diabetes. $N$ Engl J Med. (2020) 383:1425-35. doi: 10.1056/NEJMoa2004967

Conflict of Interest: The authors declare that the research was conducted in the absence of any commercial or financial relationships that could be construed as a potential conflict of interest.

Publisher's Note: All claims expressed in this article are solely those of the authors and do not necessarily represent those of their affiliated organizations, or those of the publisher, the editors and the reviewers. Any product that may be evaluated in this article, or claim that may be made by its manufacturer, is not guaranteed or endorsed by the publisher.

Copyright (c) 2021 Liang, He and Gu. This is an open-access article distributed under the terms of the Creative Commons Attribution License (CC BY). The use, distribution or reproduction in other forums is permitted, provided the original author(s) and the copyright owner(s) are credited and that the original publication in this journal is cited, in accordance with accepted academic practice. No use, distribution or reproduction is permitted which does not comply with these terms. 